\title{
Reforma do Estado e as Mudanças Organizacionais no Setor Saúde'
}

\author{
Nilson do Rosário Costa ${ }^{2}$ \\ Marcos André C. de Melo 3
}

Resumo: Este trabalho discute as transformaçôes nos modos de encarar as funções de Estado, que vêm orientando a agenda de reformas na década de 90. Aponta as implicações institucionais desse processo para o setor saúde, enfatizando os dilemas de justiça distributiva que as organizações públicas terão de enfrentar em decorrência das mudanças no modelo de gestão autárquico.

Palavras-chave: Governance; Responsabilização; Relaçôes agente/principal; Reforma do Estado.

Summary: The paper discusses the changes in the way State new responsibilities and purposes are being viewed by Brazilian society and government, after the moving on of the reform process outlined in the political agenda for the 90 s.

It highlights the consequences of this reform process upon the Brazilian Health System, addressing the current dilemmas public institutions shall face, due to their simultaneous commitment with social justice and the new methods of management and control.

Keywords: Governance; Accountability; Representative/Principal Relation; State reform.

\footnotetext{
1 Este artigo foi originalmente apresentado na oficina de trabalho "Reforma do Estado e Reforma Setorial no Brasil: Novos Modelos de Gestão", promovida pela Rede de Investigação em Sistemas e Serviços de Saúde no Cone Sul, no V Congresso Brasileiro de Saúde Coletiva, Águas de Lindóia, São Paulo, 25-26/08/1997. Ele é fruto de trabalho desenvolvido no âmbito do Projeto: Reforma do Estado e Setor Saúde, financiado pelo Programa CAPES/CNpq/FINEP. Os autores agradecem as sugestōes dos pareceristas da revista Ciência \& Saúde Coletiva.

2 Escola Nacional de Saúde, da Fundaçäo Oswaldo Cruz (ENSP/FIOCRUZ), e Universidade Federal Fluminense (UFF).

3 Universidade Federal de Pernambuco (UFPE), Recife, PE.
} 


\section{Introdução}

Este trabalho pretende identificar as principais questões teóricas e organizacionais presentes no debate sobre a reforma do Estado e apontar as suas conseqüências para o setor saúde. Propositalmente, não discutimos aqui a noção de Estado, bem desenvolvida em Evans, Rueschemeyer \& Skocpol (1985). O debate acerca da reforma do Estado situase em um cenário de difusão de novos paradigmas referentes às funçôes do Estado e da economia. Przerworsky (1995) resume estas novas interpretações como um paradigma "orientado para o mercado", em contraste com o paradigma keynesiano, prevalente nas décadas passadas, "orientado para as políticas de welfare".

O tema da reforma do Estado, ainda quando abordado numa perspectiva teórica, estaria associado à disputa pelo monopólio na definição da agenda de políticas públicas. O estudo de uma agenda permite identificar os mecanismos utilizados por agências, organizações ou atores para definir os temas substantivos de interesse público e viabilizar as suas preferências nas políticas de governo. $\mathrm{O}$ debate sobre a reforma do Estado situa-se em um cenário de difusão desta agenda: a disputa sobre as orientações relativas às funções do Estado e sua estrutura organizacional e, principalmente, referentes ao papel normatizador do mercado e seus agentes sobre a vida social como um todo (Haggard, 1995).

A grande novidade do debate dos anos 80 foi a emergência do "paradigma do mercado", exitoso na produção de um conjunto "competitivo" de idéias e percepções normativas sobre problemas, metas e técnicas relacionadas à correção das funções do Estado e à questão do desenvolvimento (Hall, 1992). Esse paradigma tem sido definido também como neo-utilitarista, monetarista ou neoliberal (Evans et al., 1995). Nos anos 80, considerava-se habitualmente tal paradigma como uma decorrência necessária da globalização econômica. Associadas aos processos de globalização e à reforma do Estado estariam também as propostas de "ajuste estrutural", difundidas por agências internacionais. $O$ ajuste estrutural é referido ao conjunto das políticas econômicas "ortodoxas" de estabilização macroeconômica, que enfatizam a imposição de constrangimentos nas políticas monetária e fiscal, liberação dos mercados de bens e serviços, desregulamentação, redução de barreiras e controle externo sobre as atividades econômicas e privatização de empresas estatais.

A força supranacional dessas orientações normativas do ajuste estrutural teriam influenciado as decisões de ajuste organizacional do Estado. A difusão gerou, segundo Haggard e Kauffman (1992:170), "substancial estreitamento, ao longo dos anos 80, das opções viáveis de politicas como conseqüencia do fortalecimento do papel das instituições financeiras internacionais e das mudanças na visão intelectual sobre a problemática do desenvolvimento".

A referência dos autores à "mudança, em escala internacional, da visão intelectual" sobre a problemática do desenvolvimento permite assinalar, além dos aspectos estritamente econômicos, a presença competitiva dos diferentes paradigmas de políticas que visam definir o formato e a velocidade com que as pautas de "ajuste organizacional" são adotadas. Está variável não-econômica torna defensável a tese sobre os tempos diferenciados de difusão, assimilação e aplicação dessas políticas pelas economias nacionais.

Ainda assim, a orientação para o mercado encontrou, durante os anos 70 a 90, condições extremamente favoráveis de crescimento, graças à construção da percepção, entre as elites políticas e profissionais, de esgotamento dos instrumentos do keynesianismo para a solução do dilema desenvolvimento ou redistribuição.

A orientação utilitarista trouxe para o centro do debate da política econômica a 
ênfase na redução dos impostos e gastos públicos, a revitalização da competição de mercado e a limitação na provisão estatal de serviços. A crítica dirigida à orientação keynesiana destacou os efeitos regressivos sobre as economias nacionais da combinação dos altos impostos, excessiva regulação, intervencionismo estatal e provisão direta de proteção social. Derivam desse diagnóstico as idéias sobre "a ameaça dos gastos sociais" ao desempenho macroeconômico e à capacidade de investimentos produtivos.

A excessiva "desmercantilização" das várias esferas da produção capitalista, favorecidas pela intervenção do Estado de bem-estar keynesiano imobilizaria recursos e geraria problemas de eficiência (Offe, 1984). Segundo Przeworsky, ao final da década de 70 , pensadores progressistas e conservadores convergiam para o diagnóstico da crise de legitimação dessa visão de Estado. Tal crise foi potencializada pela crescente necessidade de retirar recursos da esfera do mercado e tomar decisões segundo critérios não-mercantis (Przeworski, 1996).

As idéias neo-utilitaristas ressurgiriam, portanto, associadas à crise do modelo de desenvolvimento baseado na intervenção crescente do Estado na regulação do mercado, na produção do desenvolvimento e na provisão de infra-estrutura social. Estas interpretações sobre a crise do Estado de bem-estar e das orientações keynesianas foram substancialmente fortalecidas, ao longo da década de 80 , pela crise de legitimação e dissolução dos regimes socialistas de Estado do Leste europeu. Habermas (1990) caracterizaria o fim desses regimes como decorrente de uma crise de desempenho. O modo de gestão dessas sociedades, que hipertrofiou as funções do Estado, teria favorecido uma situação de estagnação tecnológica e de crise motivacional. Essa percepção da crise de desempenho das orientações de governo alicerçadas no Estado provedor e desenvolvimentista favoreceu a ampla difusão dos paradigmas de políticas centradas no mercado e o programas flexibilização das funções do aparelho estatal.

\section{Estado e Mercado}

Esse desencantamento "endêmico" com o Estado, como apontam Evans et al. (1995), tem minimizado o seu papel na promoção do desenvolvimento por meio do fortalecimento das funções do mercado. A comunidade de especialistas em economia tornou hegemônicas as visões sobre o Estado baseadas na idéia de sua "captura" por interesses particulares, ao tomarem como pressuposto teórico a impossibilidade de qualquer conduta virtuosa dos agentes públicos em prol do bem coletivo.

Segundo essa concepção negativa do aparelho estatal, as "relações de troca" entre atores do Estado e suas bases de apoio seriam a essência da ação dos agentes públicos. Para manter suas posições de direção, tais agentes têm que prover suas bases com incentivos especiais - subsídios, empréstimos, empregos, contratos ou provisão de serviços - ou utilizar o poder regulatório para criar "renda" para os segmentos políticos que os protegem, restringindo a capacidade das forças de mercado atuarem.

A legislação de proteção aduaneira ou a legislação restritiva à entrada de produtos externos em qualquer economia doméstica é tomada como um exemplo expressivo de coalizão por rendas de monopólio. A hipertrofia da regulação estatal, longe de qualquer fim altruísta, serviria, em qualquer contexto, como fonte de renda para os dirigentes públicos. A busca pelos empregos em funções públicas é, nesse argumento, reduzida à competição por rendas. Os altos ganhos em atividades oportunistas não-produtivas dominariam as atividades produtivas gerando ineficiência e declínio econômico (Evans et al., 1995). 
A partir desta definição do uso do aparelho estatal como fonte de renda, são definidas as condutas rent seeking, isto é, os mecanismos para a aquisição de renda extramercado pela ocupação de lugares na máquina pública. Essa formulação é atraente pela convergência com as descrições das relações predatórias das elites com o Estado nos países periféricos. Permite também analisar, como o fizeram os estudos sobre clientelismo $\mathrm{e}$ patrimonialismo, a incapacidade de as máquinas públicas produzirem bens coletivos devido à apropriação destes por parte das elites. O que mais surpreende é sua aplicação às formas estatais de sociedades desenvolvidas, onde teoricamente encontraríamos uma burocracia do tipo ideal, altruísta e imbuída do interesse público.

A tradição dos estudos da moderna burocracia, iniciados por Weber - como alternativa à privatização da esfera pública pelas elites arcaicas -, definiu a burocracia fundada na autoridade racional-legal, que assumiria funçôes oficiais por meio de concursos e desempenho em carreiras públicas. $O$ ingresso nessas funções de modo meritocrático daria o necessário insulamento às pressões dos interesses do mercado político. Além disso, os incentivos da carreira burocrática preveniriam o uso predatório das oportunidades públicas.

Este enfoque sobre o Estado pretende, no entanto, ir além desta solução, que inspirou as reformas anteriores do serviço público. Para escapar dos efeitos deletérios da hipertrofia das funções do Estado, essa teorização propõe a redução ao mínimo da esfera pública e, onde for possível, a substituição do controle burocrático pelos mecanismos de mercado e por relações contratuais (Pzreworsky, 1995; 1996).

A economia política tem convergido para a concepção do "direito público" sobre o papel do Estado: as denúncias de "privatização" dessa esfera, patrimônio do discurso progressista, apresentariam uma elevada convergên- cia com as teses neoconservadoras sobre as disfunções do Estado, pela constatação de que a sociedade estaria sendo vitimada pelas práticas generalizadas de rent seeking (Bresser Pereira, 1997).

\section{A Crise do Estado Brasileiro e a Agenda da Reforma}

As análises sobre o Estado brasileiro têm refletido intensamente as preocupações com a crise dessa esfera construídas ao longo de três décadas. Essas análises, no entanto, foram inspiradas, em um primeiro momento, por uma visão fundamentalmente informada pela contabilidade pública, centrando-se no que foi denominado "crise fiscal". Sustentouse que a causa fundamental da crise econômica brasileira seria o desequilíbrio financeiro estrutural do setor público associado ao tamanho excessivo da dívida externa pública. A situação crônica de desequilíbrio das finanças públicas levaria à diminuição da capacidade de poupança pública, fragilizando as tarefas desenvolvimentistas e imobilizando o Estado no tocante às reformas estruturais (Bresser Pereira, 1992).

Uma segunda linha de crítica voltou-se mais especificamente para o desenho institucional do Estado na forma desenvolvimentista. Localiza a origem da crise em variáveis organizacionais, comprováveis pela desarticulação administrativa, pela perda de capacidade de planejamento e pela ingovernabilidade.

Para Fiori (1989:105), por exemplo, a presença do Estado como epicentro desse quadro de crise explicava-se " na medida em que lo Estadol condensa, em sua desarticulação e impotência atuais, contradições embutidas em compromisso fundante que foram dribladas, através de décadas, pela possibilidade de crescimento econômico continuado e exercício autoritário incontestável de poder". A desaceleração do crescimento da econo- 
mia, em alguns anos da década, teria afetado "brutalmente" o volume de recursos e a capacidade de gastos, levando ao esgotamento "o limite da eficácia possível" do Estado desenvolvimentista.

Esses diagnósticos da crise ofereceram a sustentabilidade necessária para os projetos que se afirmaram ao longo da década de 90 em defesa de um novo desenho para o Estado brasileiro e foram efetivos na produção de um alto grau de legitimação dos argumentos sobre a crise de paradigmas, a insolvência fiscal e o colapso organizacional; considerados válidos para as funções e organizações públicas, ainda que nem sempre verdadeiros.

Em resumo, os efeitos da crise de natureza especificamente fiscal teriam levado as empresas estatais e as instituições públicas a uma situação de ineficiência estrutural pela incapacidade de gerar recursos para novos investimentos e de assegurar qualidade e baixo custo dos serviços.

Esta ineficiência estrutural teria transformado o conjunto de empresas e organizações públicas-estatais em um pesado ônus para as administrações e fonte crescente de insatisfação dos cidadãos/usuários com a qualidade dos serviços públicos de modo geral. Seguindo essa linha de raciocínio, chegou-se à conclusão de que quanto menos Estado, melhor seria para a dinâmica do mercado e para a qualidade de vida dos usuários.

A alta legitimidade da agenda de privatização das empresas estatais prende-se a este consenso sobre os efeitos perversos da ação pública na provisão de serviços. Livre das amarras da provisão direta de serviços transferíveis ao setor privado, o Estado minimizado poderia ocupar-se de funções mais estratégicas e de justiça redistributiva na área social, deixando para o mercado a provisão de bens de infra-estrutura (telefonia, energia, rodovias, saneamento etc.).

Esse novo desenho do Estado brasileiro passou a ser adotado como orientação válida para a toda federação, diante da impossibilidade do governo federal e dos governos estaduais e municipais gerarem investimentos produtivos ou manterem a qualidade dos serviços públicos, devido ao comprometimento de suas receitas com as aposentadorias dos servidores, os salários dos ativos ou os pagamentos da dívida pública. Essa adesão à agenda da reforma tem levado os governos locais à adoção de programas de privatização de empresas públicas, aos Planos de Demissão Voluntária, bem como às estratégias de terceirização destinadas a reduzir custos da força de trabalho do setor público.

\section{Reforma Administrativa e Crítica ao Modelo Burocrático}

O consenso entre analistas e gestores resultou na formulação de um projeto abrangente e complexo para a Reforma do ApareIho de Estado brasileiro. Nesse projeto aponta-se como centro a crise de inefetividade e de ineficiência na administração pública direta, que favorecera apenas a estabilidade, o formalismo e a autonomia da burocracia pública, reduzindo o controle dos cidadãos sobre as decisões dos administradores.

Esse arranjo teria contribuído para a estagnação da administração pública que (i) não incorporou novas formas de gestão; (ii) voltou-se para o controle de procedimentos e não de resultados; e (iii) inibiu a participação mais direta da sociedade na gestão pública. Esta combinação resultaria em condutas rent seeking por parte dos dirigentes públicos, pela ausência de mecanismos de responsabilização (accountability) sobre suas decisões e escolhas. Essa formulação de reforma do Estado apresenta, além disso, uma proposta abrangente com vistas a um novo desenho institucional para as funções autárquicas, públicas e privadas até então em mãos do Estado, sem se restringir às dimensões administrativas. 
A crise do Estado brasileiro apresuntarse-ia como uma crise de governance, ou zeja, de baixa capacidade dos governoi de tomar realidacle as decisões de políticas públicas pelo elevado grau de insulamento da burocracia e pela inexistência de mecanismos de flexibilização da gestão.

O conceito de governance adquiriu centralidade nessa orientaçào referente à reforma do aparelho de Estado brasileiro. O conceito está ancorado numa problemática nrais ampla sobre o papel das instituições - e do impacto da qualidade da matriz institucional de uma sociedade - no desenvolvimento (March \& Olsen, 1989; North, 1990).

As instituiçôes podem ser entendidas como "regras formais, procedimentos de observância dessas regras e práticas regulares operativas que estruturam o relacionamento entre individuos e as várias unidades do sistema político e da economia" (Hall, 1992:96). $\mathrm{Ou}$ como "regras formais, constrangimentos informais e formas de se assegurar seu cumprimento" (North, 1990:386). Para Bates (1988), as instituições representam "investimentos". As sociedades criam instituiçôes da mesma forma que firmas têm set up costs ao tazerem investimentos; seus custos são amortizaclos ao longo do tempo na forma de um ambiente estável para as transações (Tsebelis, 1997).

No contexto de informação inconıleta e incerteza os indivíduos têm altos custos para obter informação relevante sobre o que eles ou com quem eles estão transacionando. Numa sociedade na qual as instituições estão insuficientemente desenvolvidas e consolidadas, tais custos são proibitivos e inibenn um número potencialmente gigantesco de transações. A existência de instituições permite uma economia coletiva de custos de transação, gerando ganhos para toda a sociedade. Na ausência de incerteza e oportunismo, as instituições poderiam ser substituídas por promessas. Sob incerteza e oportunismo, as promessas dão lugar a contratos cuia validade e cump:imento (enforcement) são assegurados por regras.

As instituições - ou pelo menos as boas institu:ções - servem para superar dilemas de ação coletiva e situações conhecidas na literatura subre escolhas racionais como dilemas do prisioneiro (Shepsle, 1989; Lane, 1993; Gedcles, 1995). Esse conceito descreve situações em que a melhoria das posições dos membros de uma coletividade deixa de ser realizada porque os indivíduos nào têm incentivos para promovê-las unilateralmente. Nessas situações, o comportamento não-cooperativo deixa de produzir esta melhoria global na situação dos indivíduos. Como assinala North (1990), soluções exitosas desses dilemas têm implicado a criação de instituições que, nos termos da teoria dos jogos, aumentam os benefícios das escolhas cooperativas ou aumentam os custos da defecção e que, cm termos de análise de custos de transaçau, reduzem os custos de transação e produçào a cada troca, de forma que os ganhos de troca se tornam realizáveis. Tais ganhos (gains from trade) representariam o aumento global dà bem-estar resultante do intercâmbio inutuamente benéfics (ou troca econômica) entr: dois parceiros com dotaçôes de recursos diferenciados.

$\mathrm{N} \ddot{i}$ formulação do Banco Mundial, governance é definida como "a maneira pela qual o poder é exercido na administração dos recursos econômicos e sociais tendo em vista o desenvolvimento" (World Bank, 1992). Nessa visão o conceito se distingue do de governabilidade que descreve as condições sistêmicas de exercício do poder em um sistema político. Enquanto a governabilidade se refere às condições do exercício dla autoriclade política, governance qualifica o modo de uso dessa autoridade (Melo, 1995).

A capacidade de governance implica a capacidade governamental em criar e assegurar a prevalência - ou seja, a capacidade de enforcement - de regras universalistas nas transaiòes sociais, políticas sociais e econô- 
micas, penalizando ou desincentivando o comportamento rent seeking, bem como promovendo arranjos cooperativos e reduzindo os custos de transação. Do ponto de vista político, governance implica também a capacidade de resistência à captura por grupos de interesse por parte das elites governamentais (Frischtak, 1994), assim como a promoção da accountability (Przeworski, 1995; Diniz, 1995). Como assinala um documento do Banco Mundial "a accountability está no centro da boa governance e refere-se a tornar os governos responsáveis por suas ações" (World Bank, 1994:12).

O conceito de governance também é utilizado com referência a formas e mecanismos de coordenação e cooperação não necessariamente ancorados no uso da autoridade pública, como nos casos amplamente referidos pela literatura sobre processos de autoregulação e "governo privado" (embora neste último o Estado esteja presente). Nesse sentido mais amplo, governance ou governance system é definido como a "totalidade de arranjos institucionais - incluindo regras $e$ agentes que asseguram o cumprimento das regras - que coordenam e regulam transações nos limites e fora dos limites de um sistema econômico" (Hollingsworth et al., 1993). Nessa perspectiva, a análise transcende o plano meramente institucional-governamental $\mathrm{e}$ inclui mercados, redes sociais, hierarquias e associações como modos alternativos de governance.

O debate sobre a reforma do Estado brasileiro aponta essa alternativa como a oportunidade de estruturar a governance pela escolha de um Estado distanciado das tarefas desenvolvimentistas e de provisão, fortalecendo as funções de promotor e regulador do desenvolvimento.

Este diagnóstico conduziria a quatro processos básicos de reforma do Estado brasileiro: (i) a delimitação das funções do Estado, minimizadas por meio de programas de privatização, terceirização e "publicização" (cria- ção de um terceiro setor "público não-estatal" - organizações sociais), para a provisão de serviços sociais e científicos, hoje sob gestão de organizações estatais; (ii) redução do grau de interferência do Estado ao efetivamente necessário por meio de programas de desregulação dos sistemas de proteção tarifária e da produçâo interna, transformando o Estado em promotor da capacidade de competição do país no plano internacional ao invés de protetor do mercado interno; (iii) aumento da governança, através de ajuste fiscal e organizacional, de modo a garantir a autonomia financeira do Estado. A reforma administrativa implantaria a administração pública gerencial, no lugar do modelo burocrático atual, e a separação, no nível das atividades, entre formulação de políticas públicas e a sua execução; (iv) fortalecimento da governabilidade por mecanismos de responsabilização e fortalecimento das instituições políticas que garantam uma melhor intermediação de interesses e tornem legítimos e democráticos os governos.

\section{Relações Contratuais, Eficiência e Responsabilização}

Essa mudança das funções indica a opção por um Estado essencialmente regulador das relações contratuais ou das concessões aos agentes não-estatais de atividades de interesse ou relevância pública, como nas áreas de infra-estrutura e de serviços sociais. Tal opção asseguraria uma razoável equação entre eficiência e responsabilização desses agentes que executam, por meio de entes privados ou organizações sociais, as tarefas contratadas ou clelegadas pelo Estado.

Reformar o Estado, dentro deste modelo, consiste essencialmente numa tarefa de redesenho da estrutura de incentivos com que os atores se deparam, de forma a assegurar a prevalência de padrões de cooperação e da racionalidade coletiva sobre os interesses 
setoriais. O desenho dessa estrutura de incentivos é tarefa complexa porque tal opção não deixa de lidar com o trade off entre eficiência e accountability, que tem ocupado lugar importante nas discussões sobre a reforma do Estado.

O neo-institucionalismo econômico desenvolveu instrumentos analíticos para a análise das transações sociais em situações de mercado e fora dele - como é o caso de contextos organizacionais e hierárquicos (privados ou públicos). Nesse sentido, busca-se superar a dicotomia tradicional Estado versus mercado, deslocando a análise para a estrutura de incentivos que produzem resultados racionais do ponto de vista coletivo. Como assinala Przeworski (1992:51):

“ (...) falar do mercado como um objeto de intervenção do Estado obscurece o ponto principal: o problema que encontramos não é a questão do mercado versus o Estado, mas dos mecanismos institucionais especificos que podem trazer incentivos e informação aos agentes econômicos privados, e de um Estado que os leve a se comportarem de forma socialmente racionat".

As reformas econômicas, inspiradas no repertório de políticas da agenda neoliberal, têm exigido um Estado intervencionista não apenas para introduzir mudanças (o que é reconhecido por alguns defensores clessas reformas), mas para dar sustentabilidade ao funcionamento do próprio mercado.

O neo-institucionalismo econômico explora o impacto da incerteza nas transaçôes sociais. Nesse quadro analítico, adota-se um paradigma contratualista para examinar as instituições e a interação entre indivíduos ou grupo de indivíduos nessas instituições. As transações podem ser representadas como contratos entre duas partes. O neo-institucionalismo econômico se desenvolveu inicialmente na área da teoria da firma e da organização industrial, expandindo-se nas áreas da economia do trabalho, da teoria do mercado de capitais e da teoria do desenvolvimento econômico.

No âmbito das relações hierárquicas, das organizações e burocracias, das relações no mercado, ou ainda, no quadro das instituições políticas, as transações sociais podem ser modeladas pelo enfoque da relação agente e principal. No âmbito de organizações e burocracias, o agente representa o empregado contratado pelo principal para realizar uma tarefa pré-especificada. No âmbito do mercado, o fornecedor representa o agente que é contratado para produzir bens e serviços para uma empresa conforme o que se estipula em um contrato. No âmbito do sistema político, os políticos recebem uma delegação do grupo de "cidadãos-principal" para agir em seu nome. No moderno mundo corporativo, em que há uma separação entre propriedade e controle gerencial, os acionistas representam o principal e os executivos os agentes. Em todas essas situações pode-se identificar uma situação pré-contratual ou delegativa e uma situação pós-contratual ou de titularidade. No campo da atenção à saúde, essa relação é explorada por Smith et al. (1997). Oportunismo é o conceito central para analisar a relação agente/principal. Tal conceito descreve a discrepância entre o comportamento dos indivíduos ex ante e ex post face a uma situação contratual. Como os indivíduos e firmas têm competências específicas e, ao mesmo tempo, existe uma assimetria de informação entre agente e principal, surge o espaço para o oportunismo.

As situações de manifestação de oportunismo ex post são descritas pelo conceito de risco moral (moral hazard). O exemplo típico é a situação do seguro para automóvel, no qual o preço da apólice de seguro é calculado com base numa expectativa de que o comportamento do contratante, em termos de aversão a risco, se mantenha no mesmo nível da situação pré-contratual. Uma vez realizada a transação, o seguro passa a representar um 
risco moral - um incentivo perverso - para que o indivíduo se exponha a riscos maiores do que usualmente fazia na situação précontratual. Na mesma linha, na clécada de 70, a introdução de seguros de depósito para bancos comerciais criou uma situação de risco moral para esses bancos na medida em que estes poderiam realizar operações de empréstimos e crédito arriscadas sem ter o risco de perder clientes. O seguro passou a inibir o comportamento prudente por parte dos clientes na escolha de instituições financeiras.

A aplicabiliclade do conceito é ampla. Ele permite descrever arranjos institucionais e práticas de governo. Tecnicamente o risco moral se refere às situações em que há incentivos para que o custo marginal privado de uma ação se afaste do custo marginal social. Enquanto o conceito de risco moral resulta da "não-observabilidacle" do comportamento do agente numa situação pós-contratual, o de seleção adversa (adverse selection) resulta da "não-observabilidade" da informação, valores e objetivos que norteiam as decisões do agente.

No caso de recrutamento de pessoal, o principal tenclerá a atrair um grande número de candidatos não qualificados a um cargo e terá dificuldade em clistinguir o indivíduo qualificado daqueles que alegam oportunisticamente dispor das mesmas qualificações. Da mesma maneira, indivíduos com riscos (e custos) mais altos são os mais prováveis de contratar seguro para cobrir tais riscos. As empresas de seguro se deparam, portanto, com um problema de seleção adversa quando lançam planos de saúde.

Przeworski (1995:8) argumenta que três classes de relações são essenciais: a relação entre o Estado e os agentes econômicos privados, a relação entre os cidadãos e o Estado e a relação entre agentes do Estado, em particular os burocratas, e os políticos. Sua tese central é de que "a eficiência de um sistema econômico depende do desenho das relações agente/principal'.
Contudo, os problemas associados à relação agente/principal aparecem especificamente no centro da vida democrática de duas formas essenciais: em primeiro lugar na questão cla representação política. A relação entre cidadãos e seus representantes pode ser vista como uma relação na qual os representantes são agentes dos cidadãos (principal). As várias formas institucionais de tomada de decisão coletiva (plebiscito, referendum, câmaras legislativas, entre outras) são soluções alternativas para resolver problemas de informação assimétrica e oportunismo. As formas de democracia direta buscam minimizar esses problemas, mas os custos de transação envolvidos na generalização de plebiscitos para o conjunto das decisões de governo seriam inimagináveis. No processo eleitoral os cidadãos se deparam com problemas de seleção adversa porque encontram grandes dificuldades em distinguir os candidatos que apresentam promessas de comportamento futuro.

Na situação pós-contratual - isto é, após as eleições - os eleitos se deparam com o incentivo ao risco moral e podem mudar seu comportamento, isto é, podem renegar as promessas de campanha (como amplamente corroborado pela história política). Como os agentes só dispõem de mecanismos débeis de controle, muitas reformas institucionais são propostas como forma de fortalecer tais mecanismos: diminuição do tempo de mandato, maior freqüência de eleições, revogabilidade de mandato em caso de os programas não serem implementaclos etc. A qualidade da vida democrática e a eficiência de um sistema político dependem fundamentalmente de como esses problemas são minimizados (Przeworski, 1995).

A segunda forma pela qual os problemas agente/principal adquirem grande centralidade no funcionamento do Estado moderno diz respeito à relação entre governantes e a burocracia, ou seja, como os governantes - incluindo o executivo e o legislativo - podem 
controlar a burocracia; ou ainda nos cenários de mudança das funções do Estado para um papel de regulação das relaçòes contratuais para a provisão de bens públicos. A alternativa proposta pela agenda da reforma do Estado é o desenho de agências regulatórias por meio da nítida separação entre financiamento e provisão de bens públicos. Esta separação toma forma organizacional através dos entes autárquicos - agências executivas -, dos entes públicos não-estatais - organizaçôes sociais - e de agentes privados - empresas de serviços - que nas situações de provisão de bens de monopólio natural, a exemplo da provisão de água, serão submetidos a relações contratuais e regulados por agências executivas estatais. Ainda é prematuro avaliar as conseqüencias desse desenho organizacional sobre a qualidade do governo e a magnitude dos incentivos aos comportamentos oportunistas pela não-observância do comportamento pretendido dos agentes das novas funções públicas numa situação contratual.

Cabe notar que, apesar desse ambiente de incerteza sobre a efetividade do Estado reformado, essas orientações para a mudança têm sido largamente difundidas e aceitas por gestores setoriais. As elites técnicas e a burocracia executiva têm-se apresentado como os principais atores responsáveis por um comportamento adaptativo voltado para a introdução de inovações. Não menos importantes são as funções de imposição, indução ou socialização desses novos paradigmas para as funções estatais, desempenhadas pelas agências internacionais - atores privilegiados na conformação de novos desenhos institucionais para as políticas públicas nos anos 90.

Essa permeabilidade aparece também associada ao contexto democrático, que estabelece fortes imperativos de sobrevivencia e competitividade política através do julgamento periódico pelos eleitores/clientes, aumentando nos executivos locais as preocupações com "o bom governo" e com as temáticas de "performance" setorial (Melo \& Costa, 1995).

A rapidez de difusão da agenda da reforma do Estado é um exemplo bem expressivo do mecanismo de policy bandwagoning - que poderia ser traduzido por "efeito ônibus" em políticas - que consiste no processo de emulação, pelos governos, de políticas exitosas em outros contextos. A grande difusão de orientações para a reforma da matriz administrativa do Estado, adotada até mesmo por governos locais de esquerda, pode servir como um campo privilegiado para a avaliação dos efeitos não antecipados ou não esperados das mudanças do modelo de gestão pública. Especialmente na perspectiva da justiça distributiva, e sob a ótica do acesso a bens escassos, que impõe sérios dilemas de escolha aos agentes e às organizações provedoras, como no caso da utilização da atenção médica de alto custo.

\section{Reforma de Estado e o Setor Saúde}

Concluímos esse trabalho assinalando as mudanças na estrutura organizacional do setor saúde incluzidas pelas novas orientações imprimidas à reforma do Estado. As inovações setoriais estão centradas em variáveis intra-organizacionais e na experimentação de modelos alternativos de gestão, sem afetar essencialmente os compromissos de justiça distributiva das organizaçôes públicas. As inovações aparecem bastante mimetizadas nas temáticas da reforma do Estado por apontar com freqüência o modelo administrativo direto como obstáculo ao melhor desempenho da gestão e à responsabilização das organizações públicas na área da saúde.

Essas experiências concretas, que se situam na fronteira do modelo administrativo burocrático ou legal-formal, apontam para a rápida difusão de um padrão altamente flexível de destinação de recursos estatais no mix 
público-privado, até então restrito a algumas poucas fundações hospitalares.

Apesar da variabilidade de iniciativas, é possível distinguir duas tendências de inovação. Em primeiro lugar, estão as iniciativas que buscam maximizar as possibilidades de mudanças, preservando certos princípios da gestão burocrática, pelo esgotamento das possibilidades de flexibilização e aumento de desempenho das organizações públicas. Essas experiências de inovação enfrentam alguns obstáculos jurídicos importantes, associados aos obstáculos jurídicos da estrutura "autárquica" da administração, como os planos de carreira instituídos pelo poder público, a contratação de pessoal precedida de concurso público (exceto para a execução de serviços, já largamente terceirizada), as licitaçôes e contratos subordinados à Lei 8.666, a avaliação de desempenho centralizada em meios e processos, sem importar os resultados etc.

Essas experiências dentro da fronteiras do serviço público tradicional - removendo obstáculos legais sem ferir a natureza pública da organização - procuram iniciativas viáveis de inovação por meio de mobilização ideológica (a exemplo do apelo ao "espírito público" das funções do servidor para melhorar o desempenho das organizações) e por meio de mecanismos contratuais de incentivo e coerção sobre a força de trabalho. Tais experiências são absolutamente singulares em relação à orientação para a flexibilização, sob a inspiração da reforma do modelo administrativo brasileiro. A opção por inovar procura se manter dentro das fronteiras organizacionais do serviço público, preservando a estabilidade dos funcionários, a centralização decisional no nível central, a baixa autonomia financeira das organizações, o assalariamento público das profissões (com destaque para a profissão médica), regime de compra centralizado etc.

Um segundo núcleo importante de orientação reúne as organizações em um modelo de gestão no qual a intervenção do Estado passa a ter um caráter predominantemente regulatório, podendo a prestação de serviços ser desenvolvida pelo setor não-estatal, mas de natureza pública, ou pelo setor privado stricto sensu. Investese, assim, na busca de alternativas para a organização da gestão e prestação de serviços, nas quais se incluem parcerias com a iniciativa privada, com a medicina liberal e principalmente novas formas contratuais entre o poder público e as especialidades médicas.

As mudanças operadas nas esferas estaduais e municipais nessa segunda linha têm em comum as alterações nos regimes de contratação de pessoal - flexibilizando os mecanismos de acesso -, pela não exigência do concurso público, de isonomia salarial e de planos de cargos e salários e de contrato, a partir do que cessa a estabilidade no emprego. $O$ argumento no sentido de alterar os regimes de contratação é tributário do diagnóstico sobre a baixa efetividade e eficiência do modelo administrativo burocrático/formal ou da falta de profissionais especializados em determinadas áreas e regiôes. As propostas políticas de recursos humanos do Sistema Único de Saúde (SUS), de contrato único, têm sido, assim, progressivamente abandonadas, por não mais corresponderem à realidade do sistema.

Ao contrário da política previdenciária dos anos 70, de financiamento e compra de serviços médicos no setor privado, no âmbito das reformas atualmente em curso, as formas de contratação apontadas alteram os modelos internos ao serviço público. Balanços recentes permitem que seja traçado um quadro geral da diversidade de vínculos que vem alterando o núcleo estatal da rede de serviços de saúde. As formas de compra e contratação de serviços em competição podem ser resumidas como se segue, tomando como base o documento intitulado "Situação sobre Vínculo Empregatício, Remuneração e 
Incentivos no Âmbito das Secretarias Estaduais de Saúde", de 1996, realizado pelo Conselho Nacional de Secretários Estaduais de Saúde (CONASS), em conjunto com a Coordenação Geral de Desenvolvimento de Recursos Humanos para o SUS (CGDRH/SUS/ MS) e a Organização Pan-Americana de Saúde (OPAS).

Regime Jurídico Único Próprio - caracteriza-se pelo caráter permanente e estável do quadro de servidores.

Regime Jurídico Único Cedido - caracteriza as Secretarias Estaduais e Municipais com maioria de servidores cedidos pelo nível federal, especialmente pelo ex-INAMPS.

CLT Próprio - o contrato de CLT é utilizado de diversas maneiras, tanto para trabalhos temporários visando suprir lacunas específicas, como para outros de caráter mais permanente. Para esses casos, observa-se inclusive a cessão de funcionários contratados para outras administrações.

Contratação Comissionada - é utilizada de maneira diferente na administração pública, incorporando pessoal externo ou remunerando pessoal do quadro permanente.

Terceirização para Grupos Profissionais - funciona principalmente como forma de inserção de especialistas médicos de mais difícil inserção no sistema público, como: anestesistas, neurocirurgiões, ortopedistas, oftalmologistas e cirurgiôes gerais.

Terceirização para Contratação através de Empresas - dirige-se à contratação de pessoal administrativo e de serviços diversos nas áreas de segurança, transporte, alimentação, manutenção de equipamentos, ou de profissionais especializados nas áreas de informática, laboratório, entre outros.

Terceirização para Contratação através de Fundações e Outros Órgãos Oficiais - contratação de pessoal pela CLT ou contratos provisórios através de Fundações de Apoio criadas pelo corpo de funcionários de instituições autárquicas.
Consórcios Intermunicipais - criam uma sociedade civil, de direito privado, para gerir determinado hospital, grupo de ambulatórios especializados, serviços como hemocentros, entre outros, e operam segundo regras de mercado para contratação de pessoal, ou concedem gratificações para servidores do quadro permanente, sem que estas sejam estendidas aos demais.

Credenciamento através do Código 7 e Sistema de Informação Ambulatorial - SIA/ SUS - o credenciamento de profissionais por meio dessas duas modalidades não é nova e continua sendo utilizado por grande parte das Secretarias Estaduais de Saúde. A característica básica é o credenciamento de médicos para atender nos hospitais conveniados e contratados ao SUS, estendendo-se o credenciamento aos hospitais públicos e até mesmo aos ambulatórios.

Contrato Temporário - possibilita a complementação do quadro, onde há carências ou exigência de atendimento a situações especiais.

Contrato Individual de Prestação de Serviços - caracteriza-se pela contratação para atendimento a necessidades esporádicas, na forma de trabalho autônomo.

Bolsa de Trabalho/Ajuda de Custo - vincula-se à cooperação técnica, e atende às necessidades da instituição e do contratado através da integração ensino-serviço e à complementação de quadro a custos reduzidos. Demandam a elaboração de projetos de estágios, com acompanhamento e controle do seu desenvolvimento.

Em comum, toda as inovações na gestão contemplam a possibilidade de formas de contratação fora da Lei no. 8.112/90 do Regime Jurídico Único, com estabelecimento autônomo de salários e gratificações e, em determinados casos, como o do Instituto do Coração (INCOR) em São Paulo, envolvendo seleção de clientelas e instituição de formas de co-pagamento. 
Os padrões flexíveis de gestão das organizações de saúde multiplicam-se igualmente no País, observando-se situações de maior institucionalização e transformações mais pontuais, como no caso das tabelas de compra de serviços profissionais especializados complementados por usuários, ou mesmo onde a informalidade se contrapõe diretamente à legislação vigente, como no caso de compra direta de serviços oferecidos publicamente por usuários do sistema.

Considerando as experiências nos estados do Rio de Janeiro e de São Paulo, há fortes evidências de que as mudanças intraorganizacionais no modelo de gestão podem ser concentradas em dois grandes grupos: cooperativas e fundações. As Cooperativas Médicas são arranjos legalmente instituídos e que freqüentemente vendem serviços à rede pública. Mais recentemente, alguns gestores do SUS (estados e municípios) têm recorrido a esta modalidade, simples ou combinada, para suprir deficiências em alguns setores, como no caso da compra de serviços de anestesistas, de serviços de plantonistas médicos em fins de semana pela Secretaria Estadual de Saúde do Rio de Janeiro, para os Hospitais Rocha Faria e Albert Schweitzer. As cooperativas propriamente ditas foram instituídas pela Secretaria Municipal de Saúde do Rio de Janeiro para prestação de serviços médicos e de enfermagem no Hospital Lourenço Jorge e pela Secretaria Estadual de Saúde, em regime combinado entre salário de estatutário e complementação por cooperativa, para oferecer serviços no Hospital da Posse em Nova Iguaçu/RJ.

Na cidade de São Paulo foi desenvolvida uma modalidade singular de cooperativa para a gestão do sistema local e da oferta de serviços, implementada pela prefeitura municipal: o Plano de Assistência Médica (PAS), destinado a reproduzir a sistemática dos seguros-saúde por região. Alguns hospitais de origem filantrópica, como as Santas Casas de Misericórdia, conveniados ao
SUS, têm instituído planos de saúde localizados para captar recursos diretamente de associados.

As Fundações de Apoio operam de maneiras múltiplas, tendo em comum o aporte de recursos governamentais e a busca de outras fontes de captação, seja diretamente junto ao usuário, como no caso do Instituto do Coração (INCOR), na cidade de São Paulo, ou de convênios vários, como o da Fundação Municipal de Saúde (FMS) de Niterói/ RJ. Objetiva-se, assim, maior flexibilização no gasto desses recursos, como no caso das transferências que a FMS de Niterói efetua para as associações de moradores que contratam diretamente médicos e enfermeiros para o Programa Médico de Família.

Agrega-se a isso a busca de soluções organizacionais e institucionais para fazer frente a um conjunto de restrições de caráter fiscal e financeiro, bem como à pressão dos usuários por mais e melhores serviços de saúde. É necessário assinalar, ainda assim, que o elevado grau de incerteza sobre as melhores alternativas para a gestão pública leva a que muitos governos adotem uma linha de inovação claramente experimentalista, apoiando modelos de gestão em uma situação competitiva, como é o caso da orientação para a mudança na gestão hospitalar adotada pela cidade do Rio de Janeiro (Costa \& Ribeiro, 1997).

Subjacente a esse experimentalismo nas inovações no modelo de gestão, constata-se, surpreendentemente, uma adesão ainda vigorosa a princípios de eqüidade no acesso e utilização dos serviços, ainda que os gestores façam referências à necessidade de o sistema público criar mecanismos especiais para ampliar as fontes de financiamento às organizações públicas. As inovações organizacionais em curso no setor saúde têm se esquivado diante do preceito da universalidade consagrado pela Constituição de 1988 e implementado pelo SUS. Sem negar a busca de eficiência macro e microeconômica, as experiências 
mantêm a referência normativa da universalidade do atendimento, o que acarreta um crescimento incremental na oferta de serviços. Caberá avaliar futuramente se a flexibilização e o incentivo a critérios gerenciais provocam mudanças nas escolhas das organizações, impondo critérios mais restritos e pragmáticos de eficiência em detrimento dos direitos de clientelas que não possam aportar recursos para a unidade, especialmente nos casos de demandas de alto custo ou que requerem longas internações.

Nas organizações de saúde do nível federal, as mudanças têm sido mais lentas e erráticas, a julgar pela adoção crescente de fundações de apoio, visando à flexibilidade na gestão de recursos captados na prestação de serviços e nos convênios. As organizações federais se defrontam com uma conjuntura de transição em face da grande incerteza sobre a forma organizacional mais vantajosa e de menor instabilidade no cenário da reforma do Estado. A recorrência às fundações de apoio expressa essa evidente incerteza como também a cautela do Governo Federal a respeito dos elevados custos de transação que a generalização de modalidades flexíveis de gestão acarretarão inicialmente, especialmente os custos de transação decorrentes das tarefas de monitoramento e regulação. Cautela e incerteza explicam a estratégia reconhecidamente experimental presente na implementação das primeiras organizações sociais no ano de 1997 (Congressso Nacional, 1997).

As Organizaçôes Sociais são definidas, no desenho da reforma do aparelho de Estado, como organizações públicas não-estatais destinadas a absorver as atividades publicizáveis, mediante qualificação específica, para administrar bens e equipamentos do Estado, constituídas por associações civis sem fins lucrativos orientadas diretamente para $O$ atendimento do interesse público. Essas organizações aparecem como responsáveis pela execução de atividades de natureza pública não- exclusivas do Estado, como ensino, pesquisa científica e desenvolvimento tecnológico, proteção e preservação ambiental, cultura e saúde. A provisão desses bens pelas organizações sociais serve para diferenciá-las das Agências Executivas que, nesse desenho, desenvolveriam atividades exclusivas do Estado (regulação, fiscalização, arrecadação de impostos e tributos, segurança pública etc.). As agências executivas manteriam a titularidade de autarquia e seus funcionários seriam considerados de carreira.

As organizações sociais estabeleceriam com os Ministérios a que pertencem (ministério supervisor) um contrato de gestão com definição de metas, controlado e avaliado periodicamente. Por esse desenho, as organizações públicas federais, como os hospitais, ver-se-ão sob forte constrangimento na adoção do contrato de gestão, envolvidas que estão com a provisão de bens não-exclusivos. Bresser Pereira (1995:8) afirma, por exemplo, que "os hospitais públicos deverão, em principio, ser transformados em organizações sociais, ou seja, em entidades püblicas não-estatais de direito privado com autorização legislativa para celebrar contrato de gestão com o poder executivo". As vantagens, sob o ponto de vista da flexibilização administrativa, são evidentes: autonomia na definição de plano de cargos e salários; elaboração de normas próprias para contratação e seleção; permissão de complementação salarial; regulamento próprio de compras e contratação de serviços; liberdade de execução financeira dentro do contrato de gestão e orçamentação global dos recursos estabelecida no contrato de gestão.

A variável de maior incerteza dessa proposta é a possível perda da orçamentação automática por recursos do Tesouro Nacional uma vez que, em muitos casos, as organizações deverão complementar seus orçamentos com outras fontes, por meio de convênios ou venda de bens e serviços. Para os hospitais essa opção pode ser vantajosa, sob 
o ponto de vista da eficiência, porque abre a possibilidade de introduzir cobrança para usuários com seguro-saúde ou convênios com firmas. Essa atraente saída, de qualquer modo, introduz uma lógica bastante complexa porque não define as relações dessa nova organização com a clientela "cidadã", ou seja, a que não está no seguro privado nem no mercado de trabalho formal com plano de saúde.

Esses são dilemas a que a proposta da reforma do Estado não têm respondido, tendo apenas definido um projeto genérico de separação entre financiamento e oferta, acompanhando de modo muito sumário o debate internacional (Bresser Pereira, 1995). Ou,

\section{Referências bibliográficas}

BATES, R. (1988) - Toward a Political Economy of Development: A Rational Choise Perspective. Berkeley: University of California Press.

BRESSER PEREIRA. L.C. (1995) - A Reforma Administrativa do Sistema de Saúde. Trabalho apresentado no Colóquio Técnico prévio à XXV Reunião do Conselho Diretivo do CLAD, Buenos Aires, mimeo

BRESSER PEREIRA, L.C (1997) - A Reforma do Estado dos Anos 90: Lógica e Mecanismos de Controle. Barcelona, mimeo.

BRESSER PEREIRA, L.C. (1992) - A Crise do Estado Brasileiro. São Paulo: Nobel.

CONGRESSO NACIONAL (1997) - Mensagem no. 605, mimeo.

COSTA, N. R. \& RIBEIRO, J.M. (1997) - Inovação Política e Mudança de Modelo Organizacional na Saúde. Brasília, Ipea/PNUD, mimeo.

DINIZ, E. (1995) - Governabilidade, Democracia e Reforma do Estado: Os Desafios da Construção de uma Nova Ordem no Brasil dos Anos 90. Dados 3:385-416

EVANS, P.; RUESCHEMEYER, D. \& SKOCPOL, T. (1985) - Bringing the State Back. Cambridge: Cambridge University Press.

FIORI, J.L.(1989) - Sobre A Crise do Estado Brasilei- ainda, induzindo o Ministério da Saúde a adotar programas alternativos à internação hospitalar em nome da maior racionalidade e qualidade do atendimento, como transparece na proposta da NOB/96 (Costa \& Ribeiro, 1997). Em resumo, a ambigüidade da agenda do Governo Federal se evidencia claramente na lentidão da implementação da agenda da reforma do Estado. O desenho das organizações sociais não deixa claro se o alvo é o aperfeiçoamento da qualidade das funções do Estado, introduzindo mecanismos contratuais para melhor definir seus interesses como "principal", ou apenas a busca da contenção de custos e o minimalismo moral por meio da provisão de cestas básicas de procedimentos.

ro. Revista de Economia Política 9(3):103-114.

FRISCHTAK, L. (1994) - Governance Capacity and Economic Reform in Developing Countries. World Bank Technical Paper number 254.

GEDDES, B. (1995) - Politician's Dilemma: Building State Capacity in Latin America. Berkeley: University of California Press.

HABERMAS, J. (1990) - What Does Socialism Mean Today? New Left Review 183:3-21.

HAGGARD, S. \& KAUFMAN, R. (1992) - The Politics of Economic Adjustment. New Jersey: Princenton. University Press.

HAGGARD, S. (1995) - The Reform of the State in Latin America. Trabalho apresentado na Annual Bank Conference on Development in Latin America and the Caribbean. Rio de Janeiro, mimeo

HALL, P. (1992) - The Movement from Keynesianism to Monetarism: Institutional Analysis and British Economic Policies in the 1970s. In: Sven, S.; Thelen, K. \& Longstreth, F. (orgs.) - Structuring Politics, Historical Institutionalism in Comparative Analysis. Cambridge: Cambridge University Press.

HOLLINGSWORTH, J.R.; SCHMITTER, P. \& STREECK, W. (orgs.) (1993) - Comparing Capitalist 
Economies: Variations in the Governance of Sectors. Preface. Oxford: Oxford University Press.

LANE, J.E. (1993) - The Public Sector: Concepts, Models and Approaches. Newbury Park: Sage.

MARCH, J. \& OLSEN, J (1989) - Rediscovering Institutions: The Organizational Basis of Politics. Nova York: The Free Press

MELO, M..A.C. (1995) - Ingovernabilidade: Desagregando o Argumento. In: Valladares, L. \& Coelho, M. (orgs.) - Governabilidade e Pobreza no Brasil. Rio de Janeiro: Civilização Brasileira.

MELO, M.A.C. de \& COSTA, N. do R. (1995) - A Difusão das Reformas Neoliberais: Análise Estratégica, Atores e Agendas internacionais. In: REIS, E.R. et al. (orgs.) - Pluralismo, Espaço Social e Pesquisa. São Paulo: Hucitec/Anpocs. NORTH, D. (1990) - Institutions, Institutional Change and Economic Performance. Cambridge: Cambridge University Press.

OFFE, C. (1984) - Problemas Estruturais do Estado Capitalista. Rio de Janeiro: Tempo Brasileiro. PRZEWORSKI, A. (1992) - The Neoliberal Fallacy. The Journal of Democracy. 3(2):49-57
PRZEWORSKY, A. (1995) - Reforming the State: Political Accountability and Economic Intervention. New York University, mimeo.

PRZEWORSKY, A. (1996) - On the Design of the State: A Principal-Agent Perspective. New York University, mimeo.

SHEPSLE, K. (1989) - Studying Institutions: Some Lessons from the Rational Choice Approach. Journal of Theoretical Politics 1(2):131-147.

SMITH, P.C., STEPAN, A., VALDAMIS,V. \& VERHEYEN, P. (1997) - Principal-Agent Problems in Health Care Systems: An International Perspective. Health Policy I(41):3760.

TSEBELIS, G. (1997) - Processo Decisório em Sistemas Políticos: Veto Players no Presidencialismo, Parlamentarismo, Multicameralismo e Pluripartidarismo. Revista Brasileira de Ciências Sociais 12(34):20-28.

WORLD BANK (1994) - Governance: the World Bank Experience. Washington: World Bank.

WORLD BANK (1992) - Governance and Development. Washington: World Bank. 